\title{
Mifepristone versus oxytocin for cervical ripening prior to induction of labour
}

\section{Manandhar R', Saha R2, Bajrac harya J ${ }^{3}$, Malla R ${ }^{4}$}

${ }^{1}$ Rosina Manandhar, Lecturer; ${ }^{2}$ Rachana Saha, Professor; ${ }^{3}$ unu Bajracharya, Assistant Professor; ${ }^{4}$ Rumina Malla, Lecturer; Department of Obstetrics and Gynaecology, Kathmandu Medical College, Kathmandu, Nepal.

\begin{abstract}
Background: Induction of labour is one of the most important interventions done in modern obstetric practice and the success of induction techniques depends upon its role in cervical ripening and improvement in the Bishop's score.

Objectives: This study was done to compare the improvement in Bishop's score among the women receiving oral mifepristone and oxytocin infusion to ripen the cervix prior to induction of labour at term.

Methods: This was a hospital based, prospective randomized controlled trial conducted from August 2015 to February 2016. A total 68 patients were randomized into two groups: Mifepristone group and Oxytocin group. The improvement in Bishop's score prior to and after 48 hours of cervical ripening, induction to delivery interval in vaginal delivery, mode of delivery, any adverse maternal and foetal outcome were recorded in both the groups.

Results: The study demonstrated an overall significant improvement in Bishop's score in mifepristone group compared to oxytocin group ( $p$-value=0.003). A significant number of patients in mifepristone group had improved mean Bishop's score ( $p$-value $=0.001$ ) after 48 hours of cervical ripening. There were more vaginal deliveries in the mifepristone group, with shorter mean induction to delivery interval as compared to the oxytocin group. There were no maternal side effects and adverse perinatal outcomes in both the groups.

Conclusions: Mifepristone is a good alternative to oxytocin for cervical ripening for induction oflabour.
\end{abstract}

Key words: Induction, Bishop's score, mifepristone, oxytocin

\section{INTRODUCTION}

nduction of labour is one of the most important interventions done in modern obstetric practice ${ }^{1}$. In conditions where both maternal and foetal health are on jeopardy on further continuation of pregnancy, this intervention has a very advantageous role. The availability of newer induction techniques has modified the conservative attitude one held towards induction².

The success of induction techniques depend upon its role in cervical ripening. Cervical ripening refers to the softening of the cervix that typically begins prior to the onset of labor contractions. The most commonly used method to evaluate cervical ripening is the Bishop's score as it is simple and has the most predictive value. The Bishop's score of 6 or more is considered very much predictive of successful induction and vaginal delivery ${ }^{3}$.

Add ress for correspondence

Dr. Rosina Manandhar

Lecturer, Department of Obstetrics and Gynaecology

Kathmandu Medical College, Sinamangal.

E-mail: rosinamanandhar@hotmail.com
A variety of methods have been developed to induce cervical ripening in the preparation of the cervix for labour and delivery ${ }^{4}$. Balloon catheter, stripping of the membrane, low dose oxytocin and prostaglandins are commonly used techniques. Oxytocin is the commonly used induction agent worldwide. It has been used alone, in combination with amniotomy or following cervical ripening with other pharmacological or nonpharmacological methods. Prior to the introduction of prostaglandins, oxytocin was used as a cervical ripening agent as well ${ }^{5}$. A continuous infusion of oxytocin in a low dosage (at the rate of $4 \mathrm{mIU}$ per minute) is an effective method for cervical ripening and has relatively few adverse effects ${ }^{6}$. The induced patients will often progress to spontaneous labour in eight to twelve hours. The antiprogesterone; Mifepristone is currently of interest in its role for induction of labour. It is a 19-nor-steroid that binds strongly to progesterone receptor and inhibits the activity of progesterone at cellular levels and ripens the cervix, making it an option for labour induction with no apparent maternal and neonatal side effects ${ }^{2}$. In late pregnancy, the uterus is sensitized to prostaglandins 
by mifepristone and promotes cervical dilatation and induces labour ${ }^{3}$.

The earliest study on the use of mifepristonefor induction of labour was done by Frydman and colleagues in 1992 and concluded that mifepristone induction resulted in more vaginal deliveries and required lesser doses of oxytocin. Since then numerous studies have been done comparing mifepristone with dinoprostone ${ }^{1}$, oxytocin ${ }^{7}$, placebo ${ }^{8-12}$ and misoprostol ${ }^{13}$ with promising result in its effect on cervical ripening.

In thiscontext, the aim of the present study is to compare the improvement in Bishop's score brought about by mifepristone as compared to oxytocin to ripen the cervix prior to induction of labour at term and also to compare the mode of delivery, induction to delivery interval in vaginal delivery, indications of cesarean section, any maternal side effects and adverse perinatal outcome.

\section{METHODOLOG}

This was a hospital based, prospective randomized controlled trial conducted from August 2015 to February 2016 in the Department of Obstetrics and Gynaecology, Kathmandu Medical College (KMC). Ethical approval was taken from Institutional Review Committee of KMC. The inclusion criteria were singleton term pregnancy between 37-42 weeks confirmed by early USG scheduled for induction of labour, Bishop's score $<6 / 13$, with intact membranes and reactive fetal heart rate pattern. The exclusion criteria were parity $>4$, previously scarred uterus, major cephalopelvic disproportion, medical problems like renal, hepatic, cardiovascular diseases, severe asthma and contraindications of mifepristone like adrenal insufficiency, hemorrhagic disorders, inherited porphyrias, women on anticoagulant or on long term corticosteroids.

After getting an informed consent, women who met the inclusion criteria were randomized into two groups by picking up the chits labeled Mifepristone group and Oxytocin group. A total of 68 women were enrolled in the study duration, 34 in mifepristone group and 34 in oxytocin group. A thorough history and examination were performed and Bishop's score was recorded prior to cervical ripening.

If the patient didn't go into labour/or active labour even after12 hours of induction with oxytocin, the induction attempt was considered as failed.

The Bishop's score prior to cervical ripening and 48 hours thereafter in patients who required oxytocin induction was recorded. The induction to delivery interval in vaginal delivery, mode of delivery and indications of cesarean section were recorded. Maternal complications like tachysystole, uterine rupture, and any systemic side effects like diarrhoea, nausea, vomiting, and pain abdomen were recorded. Any adverse foetal outcome like birth asphyxia, apgar score $<7$ and NICU admission were recorded in both the groups.

The data were entered in Microsoft Excel 2010 and transferred to SPSS version 20. Data were analyzed using Pearson Chi Square test, Fisher's exact test and T test. A $p$-value of $<0.05$ was taken as significant.

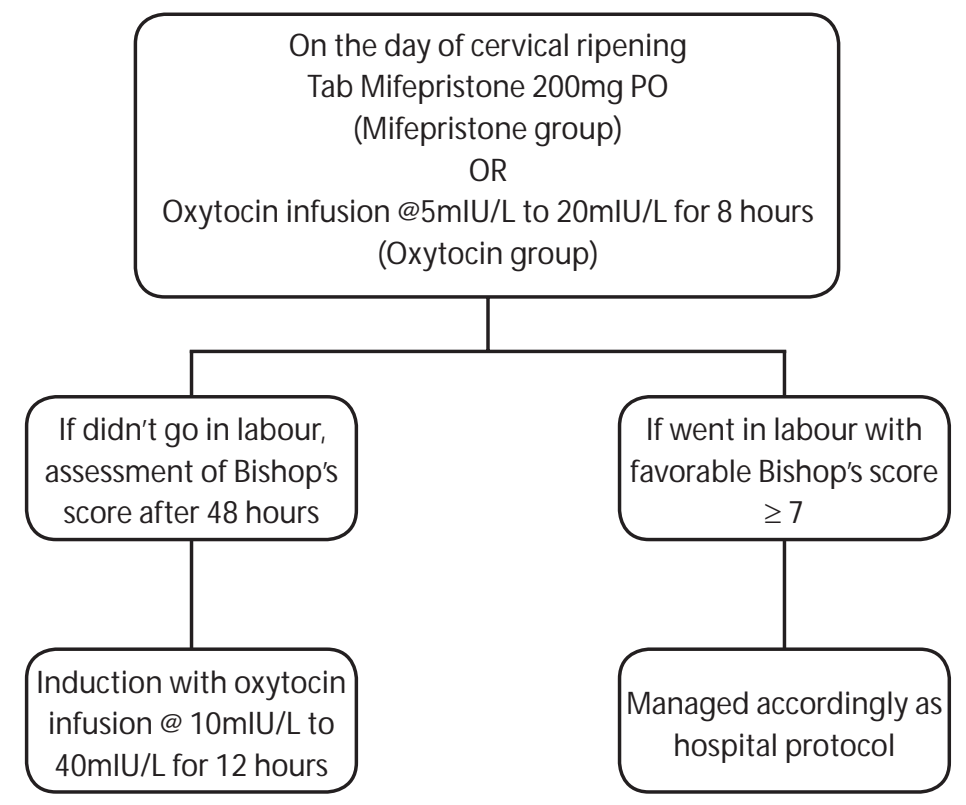




\section{RESULTS}

Both the groups were matched for maternal age, parity, indications of induction and Bishop's score prior to cervical ripening as shown in (Table 1). Mean Bishop's score prior to cervical ripening and its improvement after 48 hours in mifepristone group and oxytocin group are shown in (Table 2). There was a significant improvement in mean Bishop's score after 48 hours of cervical ripening in mifepristone group $(p<0.001)$. The overall improvement of Bishop's score was seen in $76.47 \%$ of women in mifepristone group as compared to $41.17 \%$ in oxytocin group $(p=0.003)$ and a significant number of patients had improvement in Bishop's score after 48 hours of cervical ripening, that is, $50 \%$ in mifepristone group and $14.70 \%$ in oxytocin group ( $p=$ 0.001 ) as shown in (Table 3 ). Fifty percent of women in mifepristone group had vaginal delivery and $50 \%$ had Lower Segment Cesarean Section as compared to $29.41 \%$ who had vaginal delivery and $70.58 \%$ had Lower Segment Cesarean Section in oxytocin group as shown in (Figure 1). Though not significant, the mean induction to delivery interval in vaginal delivery was shorter i.e. $6.5 \pm 1.59$ hours in mifepristone group as compared to $10 \pm 4.95$ hours in oxytocin group as shown in (Figure 2). Regarding indication of LSCS, failed induction was more in oxytocin group 17 compared to 8 in mifepristone group, however, other indications like $\mathrm{CPD}$ in active stage of labor, fetal heart rate irregularities and moderate to thick meconium stained liquor was comparable in both the groups as shown in (Table 4). There were no maternal complications like tachysystole, uterine rupture, or any systemic side effects like nausea, vomiting, diarrhea, pain abdomen. There was no adverse perinatal outcome like birth asphyxia, low Apgar score (below 7) or any NICU admission in both the groups

Table 1: Characteristics regarding age, parity, Bishop's score prior to cervical ripening and indications of induction

\begin{tabular}{|c|c|c|c|}
\hline Demographic variables & $\begin{array}{l}\text { Mifepristone group } \\
\qquad \mathrm{n}=34\end{array}$ & $\begin{array}{l}\text { Oxytocin group } \\
n=34\end{array}$ & p-value \\
\hline Age (Mean $\pm S D)$ (years) & $25.65 \pm 3.15$ & $26.12 \pm 3.68$ & 0.796 \\
\hline \multicolumn{4}{|l|}{ Parity } \\
\hline Primigravida & 24 & 23 & \multirow[t]{2}{*}{0.793} \\
\hline Multigravida & 10 & 11 & \\
\hline Bishop's score prior to cervical ripening (Mean \pm SD) & $3.53 \pm .82$ & $3.38 \pm .77$ & 0.686 \\
\hline \multicolumn{4}{|l|}{ Indications of induction } \\
\hline Post dated & 21 & 19 & \multirow{6}{*}{0.591} \\
\hline Pre eclampsia & 5 & 7 & \\
\hline Oligohydramnios & 2 & 2 & \\
\hline$I^{\prime U G R} R^{*}$ & 1 & 3 & \\
\hline$\downarrow$ fetal movement & 5 & 2 & \\
\hline Obstetric cholestasis & 0 & 1 & \\
\hline
\end{tabular}

*Intra uterine growth restriction

Table 2: Mean Bishop's score before and after $\mathbf{4 8}$ hours of cervical ripening

\begin{tabular}{|lccc|}
\hline Bishop's score & $\begin{array}{c}\text { Mifepristone group } \\
\text { (Mean } \pm \text { SD) }\end{array}$ & $\begin{array}{c}\text { Oxytocin group } \\
\text { (Mean } \pm \text { SD) }\end{array}$ & p-value \\
\hline Pre cervical ripening Bishop's score $(n=34)$ & $3.53 \pm 0.82$ & $3.38 \pm 0.77$ & 0.453 \\
\hline Bishop's score after 48 hours $(n=25)$ & $5.36 \pm 1.89$ & $3.48 \pm 0.91$ & $<0.001$ \\
\hline
\end{tabular}

Table 3: Improvement in Bishop's score

\begin{tabular}{lccc}
\hline Bishop's score & $\begin{array}{c}\text { Mifepristone group } \\
\mathbf{n = 3 4}\end{array}$ & $\begin{array}{c}\text { Oxytocin group } \\
\mathbf{n = 3 4}\end{array}$ & p-value \\
\hline Improvement in Bishop's score & $26(76.47 \%)$ & $14(41.17 \%)$ & 0.003 \\
\hline Within 48 hours & $9(26.47 \%)$ & $9(26.47 \%)$ & 1.000 \\
\hline After 48 hours & $17(50 \%)$ & $5(14.70 \%)$ & 0.001 \\
\hline
\end{tabular}


Table 4: Indications of Lower Segment Cesarean Section

\begin{tabular}{lcc} 
Indications of LSCS & $\begin{array}{c}\text { Mifepristone group } \\
\mathbf{n = 1 7}\end{array}$ & $\begin{array}{c}\text { Oxytocin group } \\
\mathbf{n = 2 4}\end{array}$ \\
Failed induction & $8(47.05 \%)$ & $17(70.83 \%)$ \\
CPD* in active stage of labor & $4(23.5 \%)$ & $3(12.5 \%)$ \\
Fetal heart rate irregularities & $4(23.5 \%)$ & $2(8.3 \%)$ \\
Moderate-Thick Meconium stained liquor & $1(5.8 \%)$ & $2(8.3 \%)$ \\
\hline
\end{tabular}

*Cephalopelvic disproportion

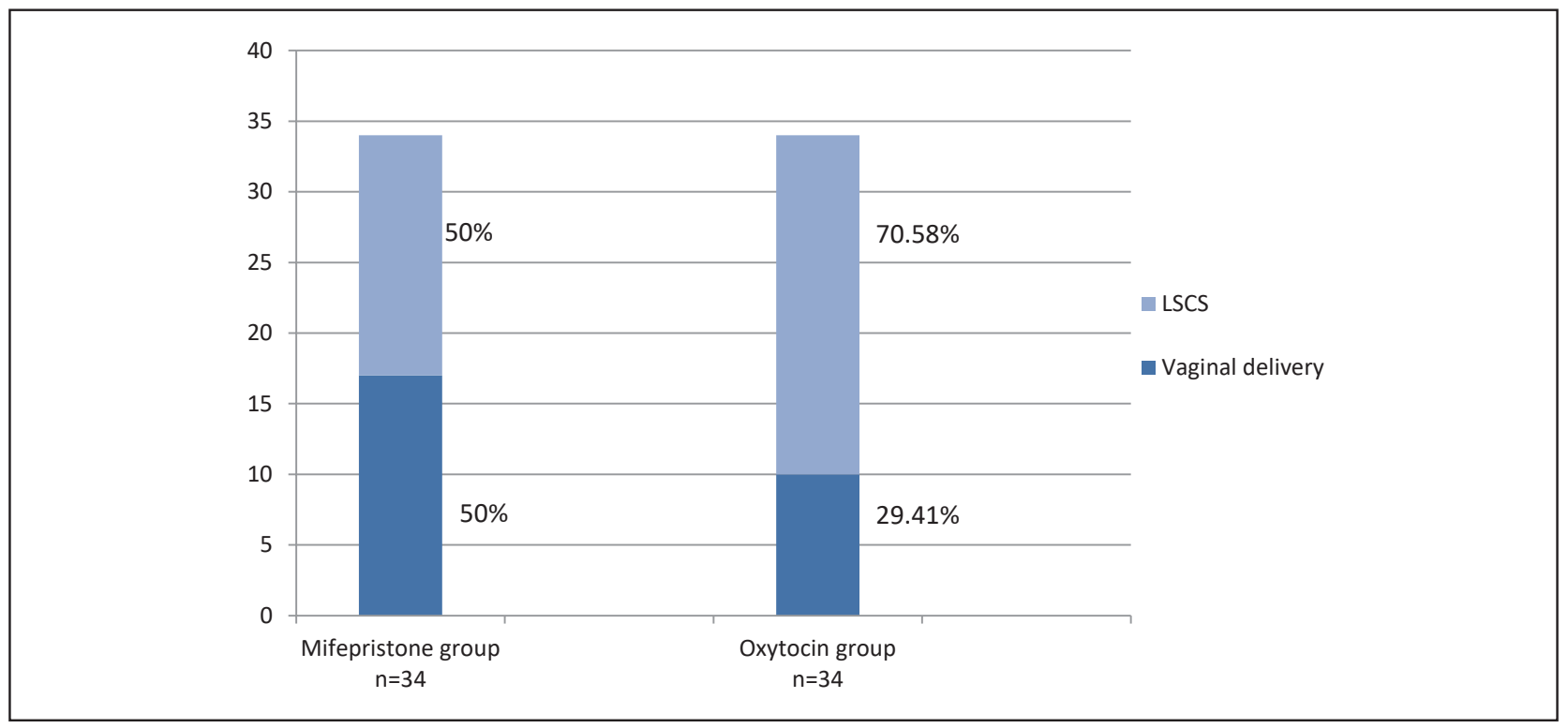

Figure 1: Mode of delivery ${ }^{*} p$-value 0.083

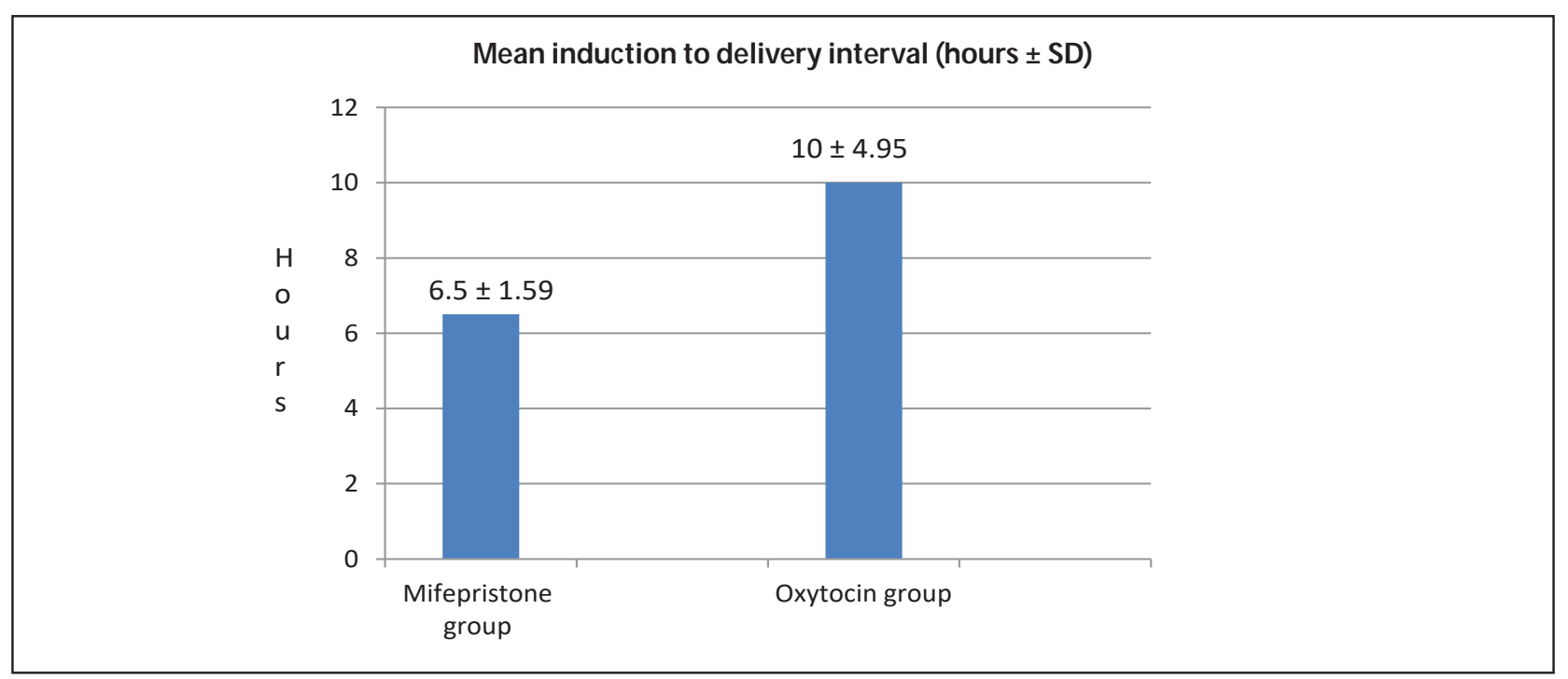

Figu re 2: Induction to delivery interval in vaginal delivery after oxytocin induction 


\section{DISCUSSON}

In the present study, the improvement of Bishop's score wasseen in asignificant numberofwomen in mifep ristone group as compared to oxytocin group. Gaikwad et al ${ }^{1}$ compared mifepristone with dinoprostone for cervical ripening prior to induction and observed improved Bishop's score in $94 \%$ of women receiving mifepristone compared to $80 \%$ women who received dinoprostone ${ }^{1}$. The higher rate of improved Bishop's score seen in their study is may be due to multiple assessment of Bishop's score at 12, 24, 48 hours, after 72 hours of cervical ripening and also when women went into active labour, whereas in our study, assessment was done only after 48 hours. So the improvement seen after 72 hours has also been reported in their study. Athawale et al observed an improvement of cervical score in $76 \%$ of women who received mifepristone for cervical ripening compared to $36 \%$ of women who received a placebo ${ }^{12}$.

In our study, a significant number of women had improvement in Bishop's score at the end of 48 hours in mifepristone group as compared to oxytocin group. This result infers that the cervical ripening was better with mifepristone at the end of 48 hours as compared to oxytocin. Stenlund et al also have reported ripened cervix in $79.2 \%$ women at the end of 48 hours with mifepristone as compared to $16 \%$ of women who received placebo ${ }^{11}$.
More vaginal deliveries were observed in mifepristone group as compared to oxytocin group, in the present study. In a similar comparative study, Gaikwad et al reported $84 \%$ of vaginal delivery in women who received mifepristone compared to $56 \%$ who received dinoprostone ${ }^{1}$. Wing et al also observed more vaginal deliveries, $78.1 \%$ with mifepristone as compared to $51.5 \%$ who received oxytocin infusion ${ }^{7}$.

As seen in our study, the mean induction to delivery time was shorter in mifepristone group ( $6.5 \pm 1.5$ hours) compared to oxytocin group ( $10 \pm 4.9$ hours). Wing et al observed shorter induction to delivery interval with mifepristone (12.8 \pm 8.6 hours) compared to oxytocin (19.9 \pm 9.4 hours) in his study ${ }^{7}$. Stenlund et al also reported shorter induction to delivery interval with mifepristone $(36 \mathrm{~h} 23 \mathrm{~m})$ compared to a placebo $(53 \mathrm{~h} 17 \mathrm{~m})^{11}$. The difference in hours seen in their study could be explained by the time taken as the beginning of induction: in our study it was taken as 48 hours after cervical ripening, while in theirs, it was from the time of cervical ripening.

\section{CONAUSON}

Mifepristone, with or without augmentation, is a good alternative agent to oxytocin for cervical ripening for induction of labour.

\section{REFERENCES}

1. Gaikwad V, Mittal B, MangalP. Comparative Analysis of Safety, Efficacy and FetomaternalOutcomeofInduction of Labour with Mifepristone versus IntracervicalDinoprostone Gel. RJPBCS.2014;5(2):611

2. Fathima S, Nayak SR, Rao B, Praveena G, ShameemVPA. Mifepristone in the induction of labour at term.Int J Pharm Biomed Res 2013, 4(3), 164-166

3. Aoron E G, Chief Editor: Carl V S. Cervical ripening. Medscape, Updated Jan 12, 2015(Cited on 2017 Jun14 ), Available from https://emedicine. medscape.com/article/263311-overview

4. Jozwiak M, Bloemenkamp KW, Kelly AJ, Mol BW, Irion $\mathrm{O}$, Boulvain M. Mechanical methods for induction of labour. Cochrane Database Syst Rev. 2012 Mar 14. 3:CD001233.

5. Kelly AJ, Tan B. Intravenous oxytocin alone for cervical ripening and induction of labour. Cochrane Database Syst Rev. 2001;(3):CD003246.
6. ACOG Committee on Obstetric Practice. ACOG Committee Opinion No. 342: induction of labor for vaginal birth after cesarean delivery. Obstet Gynecol. 2006 Aug. 108(2):465-8

7. Wing DA, Fassett MJ, Mishell DR. Mifepristone for preinduction cervical ripening beyond 41 weeks' gestation: a randomized controlled trial. Obstet Gynecol. 2000 Oct;96(4):543-8.

8. Frydman $\mathrm{R}$, Lelaidier C, Baton-Saint-Mleux C, Fernandez $\mathrm{H}$, Vial M, Bourget $\mathrm{P}$. Labor induction in women at term with mifepristone (RU 486): a double-blind, randomized, placebo-controlled study. Obstet Gynecol. 1992 Dec;80(6):972-5

9. Hapangama D, Neilson JP. Mifepristone for induction of labour. Cochrane database Syst Rev 2009(3):CD002865.

10. Yelikar K, Deshpande S, Deshpande R, Lone D. Safety and Efficacy of Oral Mifepristone in Pre-induction Cervical Ripening and Induction of Labour in 
Prolonged Pregnancy. J Obstet Gynecol India.2015 Jul; 65(4): 221-5. Doi: 10.1007/s13224-014-0584-6.

11. Stenlund PM, Ekman G, Aedo AR, BygdemanM. Induction of labor with mifepristone--a randomized, double-blind study versus placebo. ActaObstetGynecol Scand. 1999 Oct;78(9):793-8.

12. Athawale R, Acharya N, Samal S, Hariharan C. Effect of mifepristone in cervical ripening for induction of labour. Int J Reprod Contracept Obstet Gynecol. 2013 Mar;2(1):35-8

13. Li L, Gao W, Chen S. Labour induction in women at term with mifepristone and misoprostol. Zhonghua Fu Chan KeZaZhi. 1996 Nov;31(11):681-4.

14. Neilson JP. Mifepristone for induction of labour. Cochrane database of systematic reviews 2000(4):CD002865. 